\title{
Evaluation of $\beta$-blocker therapy for long- term outcomes in patients with low ejection fraction after cardiac surgery
}

\author{
Fu-Dong Fan ${ }^{1+}$, Hai-Tao Zhang ${ }^{2 \dagger}$, Tuo Pan ${ }^{1}$, Xin-Long Tang ${ }^{1}$ and Dong-Jin Wang ${ }^{1,2^{*}}$ (D)
}

\begin{abstract}
Background: Preoperative low left ventricular ejection fraction (LVEF) has been reported as an independent risk factor for in-hospital mortality. However, there were few studies evaluating the long-term mortality in these patients. We, therefore, conducted this study to investigate long-term outcomes of surgery on patients with $\mathrm{LVEF} \leq 35 \%$ undergoing a broad range of cardiac procedures.
\end{abstract}

Methods: We performed a retrospective cohort study in 510 patients from January 1, 2007 to September 1, 2019. These patients were divided into survival group $(n=386)$ and non-survival group $(n=124)$. The multivariate Cox analysis was used to estimate the risk factors for survival. In Cox analysis, $\beta$-blockers were indicated to be associated with long-term mortality. To further address bias, we derived a propensity score predicting the function of $\beta$ blockers on survival, and matched 52 cases to 52 controls with similar risk profiles.

Results: Patients were followed for a median period of 24 months (interquartile range: 11-44 months). Multivariate Cox regression analysis indicated that the non-survival group had higher weight, higher EuroSCORE, more smoking patients, longer time of cardiopulmonary bypass (CPB), more intra-aortic balloon pump (IABP) use, and more patients who always used $\beta$-blocker (HR: 2.056, 95\%Cl:1.236-3.420, $P=0.005$ ) compared with survival group. After propensity matching, the group which always used $\beta$-blocker showed higher rate of all-cause death compare with the control group (61.54\% vs $80.77 \%, P=0.030$ ).

Conclusions: The risk factors for long-term survival were weight, EuroSCORE, smoking, CPB, IABP, always used $\beta$ blockers in patients with LVEF $\leq 35 \%$. The discharge prescription of $\beta$-blocker should be cautiously administrated in those patients.

Keywords: Cardiac surgery, $\beta$-Blocker, Long-term survival

\footnotetext{
* Correspondence: dongjin_wang@126.com

${ }^{\dagger}$ Fu-Dong Fan and Hai-Tao Zhang contributed equally to this work.

'Department of Cardio-Thoracic Surgery, Nanjing Drum Tower Hospital, The

Affiliated Hospital of Nanjing University Medical School, Number 321

Zhongshan Road, Nanjing 210008, Jiangsu, China

²Department of Cardio-Thoracic Surgery, Nanjing Drum Tower Hospital,

Peking Union Medical College, Chinese Academy of Medical Sciences,

Graduate School of Peking Union Medical College, Beijing 100010, China
}

(C) The Author(s). 2020 Open Access This article is licensed under a Creative Commons Attribution 4.0 International License, which permits use, sharing, adaptation, distribution and reproduction in any medium or format, as long as you give appropriate credit to the original author(s) and the source, provide a link to the Creative Commons licence, and indicate if changes were made. The images or other third party material in this article are included in the article's Creative Commons. licence, unless indicated otherwise in a credit line to the material. If material is not included in the article's Creative Commons licence and your intended use is not permitted by statutory regulation or exceeds the permitted use, you will need to obtain permission directly from the copyright holder. To view a copy of this licence, visit http://creativecommons.org/licenses/by/4.0/ The Creative Commons Public Domain Dedication waiver (http://creativecommons.org/publicdomain/zero/1.0/) applies to the data made available in this article, unless otherwise stated in a credit line to the data. 


\section{Background}

Preoperative low left ventricular ejection fraction (LVEF) is common in patients undergoing cardiac surgery, especially those scheduled for mitral valve replacement, aortic valve replacement and coronary artery bypass grafting (CABG) [1-3]. These previous studies have shown that LVEF, typically observed in the course of the disease, was an independent risk factor for overall mortality as well as for sudden cardiac death [1-5]. However, Gambardella et al. reported that LVEF was not an independent predictor of adverse events in surgery of the descending thoraco-abdominal aorta [6]. Alternative treatment among patients with low LVEF is limited. Owing to unsatisfactory treatment, some studies suggested that these patients should receive heart transplantation [7-9]. However, the heart transplantation is also limited due to lack of organ donors [10].

A retrospective study reported that an early referral for mitral valvuloplasty would improve survival even in patients with low LEVF [3]. Many studies have shown that CABG has a good survival in patients with significant left ventricular systolic dysfunction [11-13]. A systematic review supports the concept that patients with low LEVF show a clear functional improvement after aortic valve replacement [1]. In other word, patients might benefit from these traditional cardiac procedures if they don't have donated hearts. As known, patients with low LVEF are at a higher risk for postoperative mortality [1-5]. Therefore, early recognition of patients at risk for poor outcomes plays a pivotal role in the decision making process. Several post- and peri-operative variables have been purposed as predictors of mortality, including mitral valve surgery [2], renal failure [14], low cardiac output syndrome [15], and bleeding requiring reoperation [16], etc. Nevertheless, previous studies have primarily addressed early outcomes, with limited contemporary data regarding long-term mortality in patients with low LVEF undergoing a broad range of cardiac procedures. Likewise, there are few data assessing the discharge prescriptions that might identify patients who are at highest risk. Therefore, we retrospectively analyzed our experience with patients undergoing cardiac surgery to evaluate the influence of LVEF $\leq 35 \%$ on the longterm outcomes. Furthermore, unlike some other studies $[4,11-13,16]$, we also included patients who had undergone a broad range of cardiac procedures, such as mitral valve surgery, aortic valve surgery, CABG and ventricular aneurysmectomy, etc.

\section{Methods}

\section{Study design and settings}

This study is a retrospective, observational, convenience sample study that conducted at Nanjing Drum Tower Hospital (Nanjing, Jiangsu Province, China). After receiving approval from the ethical committee of Nanjing Drum Tower Hospital, data from all patients with LVEF $\leq 35 \%$ who underwent cardiac surgery over a 10 years' period were collected. From January 1, 2007 to September 1, 2019, all consecutive patients with integrated hospital medical records, nursing records, laboratory database records, and cardiac surgery database records and undergoing a broad range of cardiac procedures were included. Patients were excluded if they were $<18$ years-old had physician-documented contraindications to $\beta$-blocker therapy [17], congenital heart disease, pregnant, any re-operations, angioplasty or thrombolytic therapy, extracorporeal membrane oxygenation (ECMO) or intra-aortic balloon pump (IABP) initiation before operation.

\section{Patient management and follow up}

All surgical operations were performed through a median sternotomy. The cardiopulmonary bypass (CPB) was used in all patients. The ascending aorta was cannulated with a patient size-appropriate cannula. Venous cannulations were chosen with separate cannulas in the superior and inferior vena cava. The initial volume of the antegrade cold blood cardioplegia solution (4:1 cardioplegia solution to blood ratio) was twice the volume needed for the cessation of all cardiac electrical activity but never less than $1000 \mathrm{~m}$. Cardiac arrest was maintained by the retrograde infusion of $300 \mathrm{~mL}$ of blood cardioplegia solution (8:1 cardioplegia solution to blood ratio) every $20 \mathrm{~min}$. Occasionally, intermittent antegrade cold blood cardioplegia was used according to the surgeon's preferences. Whenever possible, the internal thoracic artery was preferentially used for revascularization of the left anterior descending artery. Then, arterial conduits or saphenous vein grafts were used for complete revascularization. The CABG was preferentially performed if patients underwent CABG combined with valvular or other cardiac surgery. The standard surgical techniques were performed during CPB.

There were 684 patients who met the including and excluding criteria in study cohort. The follow-up ended on October 1, 2019. The data were recorded at the outpatient visit or by telephone interview. Patients were encouraged to return for a routine outpatient visit at 3 months, 6 months, 12 moths, 18 months and 24 months after hospital discharge. Researchers would visit patients when they did not have outpatient visits or telephone interviews. At each visit, patients were asked to read all of their current medications to the interviewer, including drug name, dose and schedule. In this cohort, patients were followed for a median period of 24 months (interquartile range:11-44 months), and 174 patients were lost to follow-up. Therefore, 510 patients who were not lost at follow up were included in statistic analysis and were 
divided into survival group $(n=386)$ and non-survival group $(n=124)$.

The clinical outcomes were ascertained after the 12months observational interval that was used for determining $\beta$-blocker adherence. The primary outcome was all cause death. The secondary outcomes were included refractory heart failure, stroke, refractory arrhythmia, myocardial infarction, renal failure, respiratory failure. In multivariate analysis, the continuous variables were converted to binary variables by upper quartile ( $\geq 75$ th percentile). Type of cardiac surgery included CABG, aortic valve replacement/repair (AVR), mitral valve replacement/repair (MVR), AVR + MVR, David/Wheats/Bentall procedure, CABG + ventricular aneurysmectomy and CABG + valvular surgery. In the overall cardiac surgical population, CABG is the most frequently performed operation [18], and ischemic cardiomyopathy is the most frequent cause of heart failure associated to a reduced LVEF [19]. We, therefore, use CABG to act as a reference in multivariable analysis. The continuous renal replacement therapy (CRRT) was initiated in the presence of an increase in serum creatine of more than $100 \%$ or oliguria persist for more than $4 \mathrm{~h}$ despite medications (urine output $\leq 0.5 \mathrm{ml} / \mathrm{kg} / \mathrm{h}$ ). The intra-aortic balloon pump (IABP) was initiated and implemented with standard guidelines $[20,21]$. In preoperative patients with LVEF $<35 \%$, the median follow-up time is $<24$ months in many previous studies [22-24]. Our median follow-up time is 24 months (IQR:11-44 months). The "long-term mortality" in our study may be acceptable.

\section{Statistical analysis}

IBM SPSS statistical software was used (Statistics for Windows, version 25, IBM Corporation, Armonk, NY, USA). Normally distributed variables were expressed as mean \pm standard deviation and compared using Student's t-test. Nonparametric continuous variables were expressed as median (interquartile range (IQR) and compared using the Mann-Whitney U test. Continuous variables were determined to be normal in distribution by the Shapiro-Wilk test. Categorical data were equated using the chi-square test or Fisher's exact test. The Kaplan-Meier method was used to analyze unadjusted survival, which was compared using the log-rank test. All covariates reaching a statistical significance $(P \leq 0.10)$ in univariate modeling were entered into a multivariable Cox regression model designed to assess the independent association of risk factors for survival. Collinearity diagnostics were performed using tolerance estimates for individual variables in a linear regression model.

In multivariable Cox analysis, $\beta$-blockers were indicated to be associated with long-term mortality. Because $\beta$-blockers administration was identified as a novel risk factor of survival following cardiac surgery, we further adjusted bias by using a propensity score. Therefore, with the help of this method, a comparison between patients always used $\beta$-blockers ( $\beta$-Blocker group) and those who never or inconsistently used $\beta$-blockers (control group) with similar risk profiles was made possible [25]. Before matching, there were 24 patients with no $\beta$ blocker treatment. After matching, there was no patients with no $\beta$-blocker treatment in control group. In both groups, the follow-up was completed on October 1, 2019 . However, the mortality of $\beta$-blocker group was higher than the mortality of control group. Therefore, $\beta$ blocker group has shorter follow-up length (median: 17, IQR: 8-41 months) compered with control group (median: 26 months, IQR $12-47$ months). Propensity score 1-to-1 matching was utilized with the nearest neighbor algorithm without replacement and a 0.02 caliper setting. Age, New York Heart Association (NYHA) class, history of acute myocardial infarction (AMI), smoking, type of cardiac surgery, CPB time, intraoperative bleeding, drainage on the first postoperative day (POD1), mechanical ventilation (MV) time, EuroSCORE and always use ACEI/ARB during follow up were put into a Logistic regression model to estimate the propensity score. Following matching, standardized mean differences (SMD) were used to assess the degree of baseline variable balance. The SMD between matching pairs < 0.20 reflects an acceptable balance. All reported $P$ values are two sides, and values of $P<0.05$ were considered to indicate statistical significance.

\section{Results}

A total of 510 patients were enrolled in this study. Amongst them, 386 patents were survived without any complications, while 124 patients died during follow-up. Therefore, the survival group had 386 patients, and the 124 patients were included in non-survival group. All of patients underwent CABG received on-pump procedures. Additionally, patients who postoperatively initiated IABP were implemented $\mathrm{CABG}+$ ventricular aneurysmectomy $(n=4)$ and CABG + valvular surgery $(n=8)$. The baseline and demographic variables were quite different between survival group and non-survival group (Table 1; eTable 1 and eTable 2 in the online-only Data Supplement).

\section{Univariate analysis}

Demographic and preoperative variables between survival group and non-survival group shown in Table 1 . Age, gender, weight, NYHA class, EuroSCORE, AMI, chronic obstructive pulmonary disease (COPD) and smoking associated with survival in univariate analysis. Intraoperative and postoperative differences were shown in eTable 1 (online-only Data Supplement). These variables included type of cardiac surgery, CPB time, aortic 
Table 1 Preoperative Baseline and Characteristics

\begin{tabular}{|c|c|c|c|}
\hline Variable & $\begin{array}{l}\text { Non-Survival } \\
(\boldsymbol{n}=124)\end{array}$ & $\begin{array}{l}\text { Survival } \\
(\boldsymbol{n}=386)\end{array}$ & $P$ value \\
\hline Age (year) & $57.08 \pm 13.05$ & $59.67 \pm 11.71$ & 0.038 \\
\hline Gender (male, \%) & $98,79.03 \%$ & $239,61.92 \%$ & $<0.001$ \\
\hline Weight (kg) & $66.96 \pm 11.89$ & $62.81 \pm 11.85$ & 0.001 \\
\hline NYHA class (n, \%) & & & 0.001 \\
\hline । & $5,4.04 \%$ & $9,2.33 \%$ & \\
\hline$\|$ & $55,44.35 \%$ & $109,28.24 \%$ & \\
\hline III & $55,44.35 \%$ & $228,59.07 \%$ & \\
\hline IV & $9,7.26 \%$ & $40,10.36 \%$ & \\
\hline EurOSCORE & $6.06 \pm 2.45$ & $4.54 \pm 2.08$ & $<0.001$ \\
\hline \multicolumn{4}{|l|}{ Echocardiogram variables } \\
\hline Preoperative LVEF (\%) & $30.36 \pm 4.29$ & $30.99 \pm 3.87$ & 0.124 \\
\hline Preoperative LVDd (cm) & $7.11 \pm 1.09$ & $6.98 \pm 1.05$ & 0.258 \\
\hline Evaluated PAP (mmHg) & $47.85 \pm 18.11$ & $48.24 \pm 13.66$ & 0.817 \\
\hline \multicolumn{4}{|l|}{ Previous Medical History (n,\%) } \\
\hline Acute Myocardial infarction & $62,50 \%$ & $56,14.51 \%$ & $<0.001$ \\
\hline Atrial fibrillation & $23,18.55 \%$ & $101,26.17 \%$ & 0.085 \\
\hline Diabetes Mellitus & $15,12.10 \%$ & $34,8.81 \%$ & 0.280 \\
\hline Chronic Renal Failure & $3,2.42 \%$ & $6,1.55 \%$ & 0.525 \\
\hline Hypertension & $33,26.61 \%$ & $94,24.35 \%$ & 0.613 \\
\hline Liver Disease & $4,3.23 \%$ & $14,3.63 \%$ & 0.833 \\
\hline COPD & $12,9.68 \%$ & $8,2.07 \%$ & $<0.001$ \\
\hline Cancer & $2,1.61 \%$ & $4,1.04 \%$ & 0.604 \\
\hline Smoking & $42,33.87 \%$ & $57,14.77 \%$ & $<0.001$ \\
\hline Excessive alcohol & $16,12.90 \%$ & $28,7.25 \%$ & 0.051 \\
\hline ACEI/ARB use & $2,1.61 \%$ & $14,3.63 \%$ & 0.258 \\
\hline $\mathrm{Ca}^{2+}-\mathrm{Blocker}$ use & $7,5.64 \%$ & $11,2.85 \%$ & 0.145 \\
\hline$\beta$-blocker use & 0 & $7,1.81 \%$ & 0.130 \\
\hline Statin use & $3,2.42 \%$ & $8,2.07 \%$ & 0.798 \\
\hline Diuretic use & 9 & $25,6.48 \%$ & 0.799 \\
\hline Aspirin use & 0 & 0 & - \\
\hline Clopidogrel use & 0 & $7,1.81 \%$ & 0.130 \\
\hline Levosimendan use & 0 & 0 & - \\
\hline Lyophilized Recombinant Human Brain Natriuretic & 0 & 0 & - \\
\hline
\end{tabular}

NYHA: New York Heart Association

LVEF: Left ventricular ejection fraction

COPD: Chronic obstructive pulmonary disease

PAP: Pulmonary artery pressure

LVDd: Left ventricular end-diastolic diameter

Mean \pm SD

cross clamp (ACC) time, intraoperative bleeding, postoperative CRRT, postoperative IABP and mechanical ventilation time. Patients who always used $\beta$-blockers during follow-up have been shown to be associated with survival in eTable 2 (online-only Data Supplement).

\section{Multivariate analysis}

In order to maintain the comparability between survival group and none-survival group, all covariates reaching a statistical significance $(P \leq 0.10)$ in univariate modeling were entered into a multivariable Cox regression model. 
In multivariable analysis, variables which associated with survival were shown as follows: weight $>70 \mathrm{~kg}$ (HR: 1.740, 95\%CI: 1.048-2.889, $P=0.032$ ), EuroSCORE $>6$ (HR: 2.142, 95\%CI: 1.225-3.743, $P=0.008$ ), smoking (HR: 2.146, 95\%CI: 1.034-4.451, $P=0.040$ ), CPB > 216 min (HR: 8.004, 95\%CI: 3.372-18.997, $P<0.001$ ), postoperative IABP use (HR: 30.935, 95\%CI: 10.328-92.661,
$\mathrm{P}<0.001$ ), always use $\beta$-blocker during follow-up (HR: 2.056, 95\%CI: 1.236-3.420, $P=0.005)$. Additionally, CABG + ventricular aneurysmectomy (HR: 5.683, 95\%CI: 2.474-13.054, $\mathrm{P}<0.001)$ and $\mathrm{CABG}+$ valvular surgery (HR: 4.314, 95\%CI: 1.260-14.773, $P=0.020$ ) increase long-term mortality, and MVR (HR: 0.169, 95\%CI: $0.035-0.815, P=0.027)$ decrease the mortality

Table 2 Multivariate analysis of factors associated with survival

\begin{tabular}{|c|c|c|c|}
\hline Variable & Hazard Ratio & 95\% Confidence Interval & $P$ value \\
\hline Age $>67$ years old & 0.645 & $0.343-1.214$ & 0.174 \\
\hline Gender (male) & 1.638 & $0.829-3.235$ & 0.155 \\
\hline Weight $>70$ kg & 1.740 & $1.048-2.889$ & 0.032 \\
\hline \multicolumn{4}{|l|}{ NYHA class } \\
\hline । & Reference & & \\
\hline$\|$ & 1.185 & $0.284-4.939$ & 0.816 \\
\hline III & 0.597 & $0.138-2.584$ & 0.490 \\
\hline IV & 0.973 & $0.186-5.085$ & 0.974 \\
\hline EuroSCORE $>6$ & 2.142 & $1.225-3.743$ & 0.008 \\
\hline Preoperative LVEF > 33\% & 1.378 & $0.744-2.552$ & 0.308 \\
\hline Preoperative acute myocardial infarction & 0.713 & $0.192-2.641$ & 0.612 \\
\hline Preoperative atrial fibrillation & 1.399 & $0.763-2.566$ & 0.278 \\
\hline Preoperative COPD & 1.062 & $0.457-2.468$ & 0.899 \\
\hline Smoking & 2.146 & $1.034-4.451$ & 0.040 \\
\hline Excessive alcohol & 1.170 & $0.504-2.714$ & 0.715 \\
\hline \multicolumn{4}{|l|}{ Type of cardiac surgery } \\
\hline CABG & Reference & & \\
\hline AVR & 0.307 & $0.043-2.202$ & 0.240 \\
\hline MVR & 0.169 & $0.035-0.815$ & 0.027 \\
\hline$A V R+M V R$ & 0.284 & $0.063-1.273$ & 0.100 \\
\hline David/Wheats/Bentall procedure & 0.864 & $0.191-3.910$ & 0.850 \\
\hline CABG +ventricular aneurysmectomy & 5.683 & $2.474-13.054$ & $<0.001$ \\
\hline CABG + valvular surgery & 4.314 & $1.260-14.773$ & 0.020 \\
\hline $\mathrm{CPB}>216 \mathrm{~min}$ & 8.004 & $3.372-18.997$ & $<0.001$ \\
\hline ACC $>163 \mathrm{~min}$ & 0.541 & $0.227-1.289$ & 0.166 \\
\hline Intraoperative bleeding $>1.2 \mathrm{~L}$ & 0.963 & $0.545-1.700$ & 0.896 \\
\hline CRRT & 1.190 & $0.445-3.186$ & 0.729 \\
\hline Sepsis & 0.742 & $0.198-2.785$ & 0.659 \\
\hline IABP use & 30.935 & $10.328-92.661$ & $<0.001$ \\
\hline MV time $>23 \mathrm{~h}$ & 0.985 & $0.576-1.684$ & 0.956 \\
\hline Always use $\beta$-blocker & 2.056 & $1.236-3.420$ & 0.005 \\
\hline
\end{tabular}

NYHA: New York Heart Association

CABG: Coronary artery bypass grafting

MVR: Mitral valve replacement/repair

ACC: Aortic Cross Clamp

IABP: Intra-aortic balloon pump

-LVEF: Left ventricular ejection fraction

AVR: Aortic valve replacement/repair

CPB: Cardiopulmonary bypass

CRRT: Continuous renal replacement therapy

MV: Mechanical ventilation 


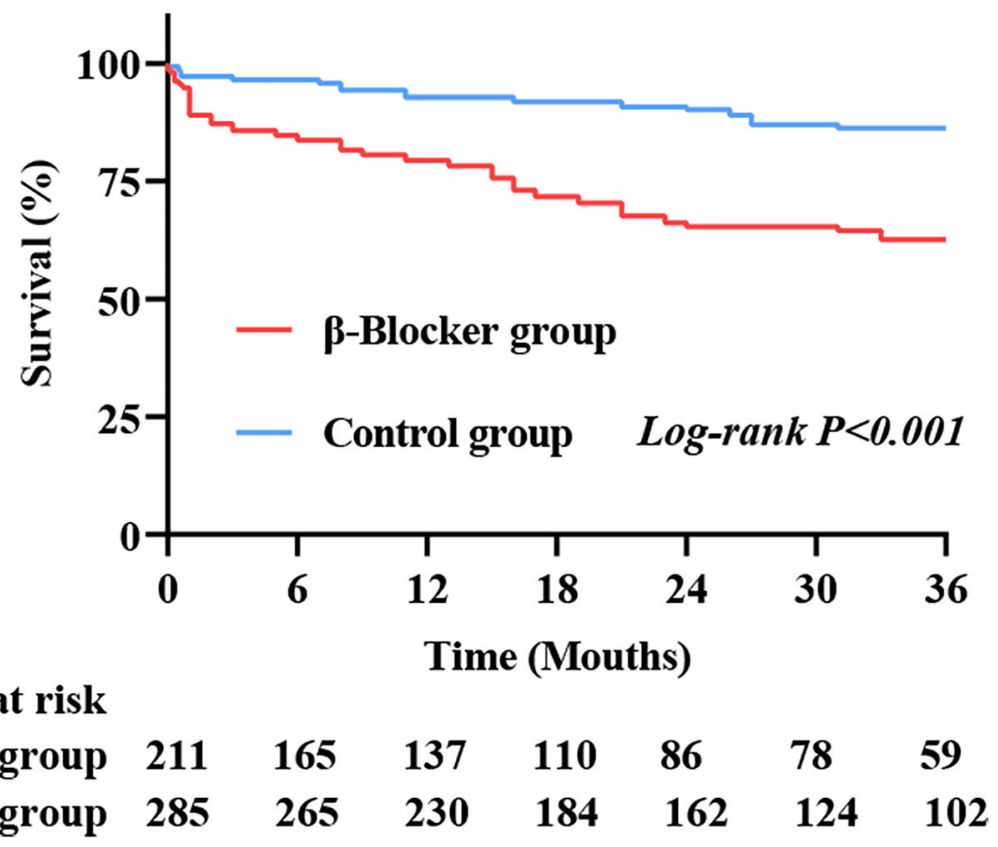

Fig. 1 Kaplan Meier survival curves of the entire study cohort, with 95\% confidence intervals (Cl), showed that $\beta$-blocker was associated with a higher unadjusted mortality (86, 95\%Cl:82-90\% vs. 62, 95\%Cl: 54-70\%, P<0.001). 14 patients who died suddenly after the operation were not included

when CABG was regarded as reference. The detail variables of multivariable Cox analysis associated with survival were presented in Table 2. Kaplan Meier survival analysis of the entire study cohort, with $95 \%$ confidence intervals (CI), also showed that $\beta$-blocker was associated with a higher unadjusted mortality (Figs.1, 86, 95\%CI: $82-90 \%$ vs. 62 , $95 \%$ CI: $54-70 \%, P<0.001)$.

Risk of long-term mortality with $\beta$-blockers in propensitymatched patients

The adjustment for selection bias was further addressed using a propensity score. Because $\beta$-blocker administration was identified as a novel risk factor of survival following cardiac surgery, we further studied this finding by pairing those who always used $\beta$-blockers with similar individuals who never or inconsistently used it. Before propensity-score matching, the absolute standardized differences of age, NYHA class, history of AMI, smoking, type of cardiac surgery, CPB time, intraoperative bleeding, drainage on the POD1, MV time, EuroSCORE and always use ACEI/ARB during follow up were - 14.6, $2.2 \%, 14.9,14.3,26.8,34.3,12.0,1.1,-19.1 \%, 0.5$ and $40.5 \%$ respectively. After matching, the absolute standardized differences of these 11 variables were 2.0, $3.2 \%, 8.2,3.5,-8.8 \%, 21.2,3.9,3.9,8.4,22.1,0.8$ and $21.6 \%$ respectively. Therefore, these variables were well balance with a decreased standardized difference and had acceptable standardized mean differences (eFig. 1 in the online-only Data Supplement). Within the group of 211 individuals always used $\beta$-blockers, we could match 52 of them to 52 similar controls. After matching, there was no significant difference between propensity-

Table 3 Association of $\beta$-blocker use at discharge and during follow-up with long-term outcomes in a matched cohort

\begin{tabular}{|c|c|c|c|c|}
\hline Variables & $\begin{array}{l}\text { Control } \\
(\boldsymbol{N}=52) \\
\end{array}$ & $\begin{array}{l}\text { Always users } \\
(\mathrm{N}=52)\end{array}$ & $\begin{array}{l}\text { Hazard ratio } \\
(95 \% \mathrm{Cl})\end{array}$ & $P$ value \\
\hline All-cause death $(n, \%)$ & $32,61.54 \%$ & $42,80.77 \%$ & $2.08(1.18-3.66)$ & 0.030 \\
\hline Refractory heart failure(n, \%) & $4,7.69 \%$ & $17,32.69 \%$ & $2.16(1.21-3.87)$ & 0.003 \\
\hline Stroke $(n, \%)$ & $13,25 \%$ & $9,17.31 \%$ & $0.63(0.31-1.30)$ & 0.337 \\
\hline Refractory arrhythmia (n, \%) & $7,13.46 \%$ & $3,5.77 \%$ & $0.44(0.14-1.42)$ & 0.183 \\
\hline Myocardial infarction (n, \%) & $8,15.38 \%$ & $9,17.31 \%$ & $1.41(0.68-2.91)$ & 0.791 \\
\hline Renal failure (n, \%) & 0 & $3,5.77 \%$ & 4.55(1.39-14.94) & 0.079 \\
\hline Respiratory failure (n, \%) & 0 & $1,1.92 \%$ & $6.36(0.84048 .19)$ & 0.315 \\
\hline
\end{tabular}

In control group, patients had never used $\beta$-blocker $(n=0)$, or inconsistently used $\beta$-blocker $(n=52)$

$\mathrm{Cl}$ : Confidence Interval 


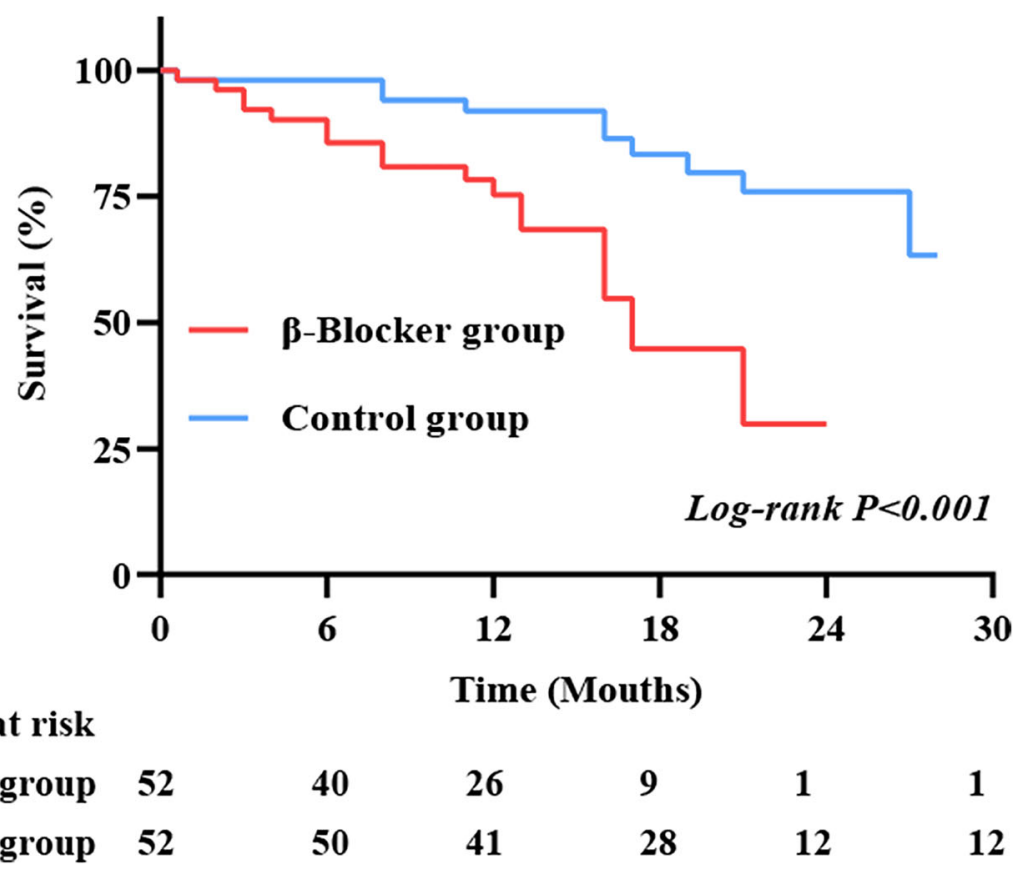

Fig. 2 After matching, Kaplan-Meier survival curves showed that the survival rate was 24, 95\%Cl:0-48\% in $\beta$-blocker group, while 74, 95\%Cl:58$90 \%$ in control group $(P<0.001)$

matched groups with regard to baseline characteristics (eTable 3 in the online-only Data Supplement). In propensity-matched patients, $\beta$-Blocker group had higher rates of all-cause death $(61.54 \%$ vs $80.77 \%, P=0.030)$ and refractory heart failure $(7.69 \%$ vs $32.69 \%, P=0.003)$ compared with control group (Table 3). After matching, Kaplan-Meier survival curve showed that the survival rate was $24,95 \% \mathrm{CI}: 0-48 \%$ in $\beta$-blocker group, while 74 , 95\%CI:58-90\% in control group (Fig.2, $P<0.001$ ).

In addition, stroke, refractory arrhythmia, myocardial infarction, renal failure and respiratory failure had no differences among two groups (Table 3). Furthermore, we further analyzed the data. The study population was divided into $\mathrm{LVEF}>35 \%$ group and $\mathrm{LVEF} \leq 35 \%$ group according to their LVEF during follow-up (eTable 4 in the online-only Data Supplement). It showed that $\beta$-blocker had not only increased the mortality in pre-matched group $(\mathrm{P}<0.001)$ but also increased mortality in matched group $(P=0.039)$ when LVEF was $\leq 35 \%$ during follow up. However, the $\beta$-blocker and control group had no differences in mortality when LVEF was $>35 \%$ during follow up $(P=0.406)$.

\section{Discussion}

The data presented in this study demonstrate that patients with low LVEF ( $\leq 35 \%)$ undergoing a broad range of cardiac procedures have poor survival $(24.31 \%)$. The risk factors for long-term survival were weight $>70 \mathrm{~kg}$, EuroSCORE $>6$, smoking, Cardiopulmonary bypass
$(\mathrm{CPB})>216 \mathrm{~min}$, postoperative Intra-aortic balloon pump (IABP) use, and always use $\beta$-blocker during follow-up. When CABG was regarded as reference, CABG + ventricular aneurysmectomy and CABG + valvular surgery are independent risk factors for long-term survival, and MVR is a preventive factor for long-term survival. Additionally, we found that $\beta$-blocker administration was associated with long-term mortality. To further assess the risk associated with $\beta$-blockers and adjust for potential biases, we paired individuals who always receive $\beta$-blockers to controls who inconsistently or never received $\beta$-blockers. On the basis of this propensity score, the Kaplan-Meier survival curves indicated that $\beta$-blocker administration was still associated with higher mortality during patient follow-up. Moreover, $\beta$-blocker could increase mortality when postoperative heart function was not improved; and might not increase mortality when postoperative heart function had been improved.

To our knowledge, this is the first study to show a relationship between $\beta$-blocker therapy after hospital discharge and increased risk for long-term mortality. It may offer new insights into the association between $\beta$ blocker therapy and long-term survival. Current evidence regarding the beneficial effect of $\beta$-blocker may be conclusive, especially in CABG patients [26-28]. In a long-term observational study of 5926 consecutive patient undergoing isolated CABG, Zhang $\mathrm{H}$ et al. reported that consistent use of $\beta$-blocker after hospital discharger was associated with a lower risk of death and composite 
cardiovascular events [26]. In a prospective cohort of 3102 patients, Chan AY et al. reported that Patients discharged with $\beta$-blockers after cardiac surgery exhibit a substantially lower mortality rate during long-term follow-up [29]. In our study, half of the patients in the non-survival group are accompanied with AMI, while $56 / 386$ in the survival group $(P<0.001)$, and all patients in current study received selective CABG. According to these previous studies, the $\beta$-blocker is routinely recommended to be a discharge prescription [26, 29]. However, we found that if heart function does not improve after surgery, $\beta$-blockers might increase mortality. For patients with significantly improved heart function after surgery, $\beta$-blockers might not increase mortality.

Several differences should be highly emphasized. Firstly, these previous studies contained a larger proportion of LVEF $\geq 50 \%$. In our study the mean LVEF is $30.83 \%$ (standard deviation: 3.97\%). In other words, the previous condition of patients in our study were worse than those in previous studies. Secondly, those previous studies had a large population of isolated CABG (>60\%). There were $17.45 \%$ patients who underwent isolated CABG in our study. It indicated that our study had broad range of cardiac procedures. Finally, we considered that all patients had received selective operation in our study, whereas there were $58.48 \%$ patients who underwent urgent or emergent operation in Dr. Chan AY' s study [29]. Patients who were discharged with $\beta$ blocker after urgent cardiac surgery may have a lower rate of death [30]. That may be the reason why their $\beta$ blocker group showed positive outcomes. Therefore, our findings reduce the evidence supporting the use of discharge $\beta$-blocker after cardiac surgery. In addition, we have addressed criticisms that the $\beta$-blockers reduce mortality in patients after various kinds of cardiac procedures [29]. A potential mechanistic explanation for our findings arose from a pharmacological analysis that demonstrated that $\beta$-blocker acted as a negative inotropic agent might further decrease the cardiac output when the cardiac function had irreversibly impaired. That is the reason why $\beta$-blocker might increase long-term mortality when heart function could not be improved during follow-up.

Our study also indicated that many factors on multivariable analysis were association with long-term survival. These risk factors including weight, EuroSCORE, smoking, $\mathrm{CPB}$ and postoperative IABP utilization. In this sense, our experience may add new clues to be implanted into clinical practice. A previous study have shown that IABP improved the outcomes in high risk patients undergoing CABG [31]. In our study, patients who postoperatively initiated IABP were implemented CABG+ ventricular aneurysmectomy $(n=4)$ and CABG + valvular surgery $(n=8)$. When CABG was regarded as reference, CABG + ventricular aneurysmectomy and CABG + valvular surgery are independent risk factors for long-term survival. Therefore, the use of postoperative IABP is a marker of severity illness rather than primary cause of a worse outcome. Finally, our study demonstrated a similar conclusion that MVR would improve survival even in patients with low LVEF [3]. It may be necessary that those patients with low LVEF should undergo MVR as soon as possible.

Limitations of the present study also need to be acknowledged. Our study design involved one center's experiences with the inherent disadvantages of a retrospective study, which is highly prone to bias. This observational study could have been influenced by potential biases. It should be indicated that our patient population might be very heterogenous, with many procedures of varying complexity pooled together. We used propensity score matching to avoid these biases. The type of cardiac surgery was regarded as one of the covariates for our propensity score matching. After the matching, the standard mean difference (SMD) of the surgical procedures of the two groups decreased from 26.8 to $8.8 \%$. Meanwhile, the $P$ value of procedures was 0.438 (eTable 3 ) after propensity matching (eTable 1 , the pre-matching $P=0.005$ ). We had tried our best to avoid the bias. However, with this analysis, we removed a large number of patients from the analysis but may have elevated the statistical errors. Furthermore, in the early period from January 2007 to December 2012, 155 patients $(155 / 230,67.4 \%)$ were lost to follow-up. However, there were 19 patients $(19 / 454,4.2 \%)$ who were lost to follow-up from January 2013 to September 2019. We did not exclude patients from January 2007 to December 2012. Because the data(2007-2013) is still valuable, important and useful to be shared when the final results are not changed (eTable 5 in the online-only Data Supplement). However, 174 patients were lost to follow-up. This accounts for as much as $25 \%$ of the whole patient population and can essentially confound the results. Moreover, we could not collect detailed data about $\beta$ blocker therapy during follow up, such as daily heart rate, timing of changed dosage and reasons of changed dosage. Finally, there were 285 patients who did not reexamine echocardiography and/or magnetic resonance imaging (MRI) after 1-year of hospital discharge in this study cohort. Therefore, we could not collect echocardiographic and/or MRI data in these patients. These factors that affect assignment to treatment and outcomes but cannot be observed are hidden bias in our study. Any hidden bias due to latent variables might have remained after matching, which could have led to some statistical errors. Thus, we recommend further highquality trials to answer questions about the mechanisms of action, effectiveness on subgroups, dose-response, 
length of therapy, functional outcome, and quality of life after $\beta$-blocker use for patients with low LVEF.

\section{Conclusions}

The risk factors for long-term survival were weight $>70$ $\mathrm{kg}$, EuroSCORE $>6$, smoking, $\mathrm{CPB}>216 \mathrm{~min}$, postoperative IABP use, and always use $\beta$-blocker during followup. Meanwhile, $\beta$-blocker might not increase mortality when heart function had been improved after cardiac surgery. The discharge prescription of $\beta$-blocker should be cautiously administrated in those patients.

\section{Supplementary information}

Supplementary information accompanies this paper at https://doi.org/10. 1186/s12872-020-01651-6.

\section{Additional file 1: eFig. 1. The standardized mean difference was visually presented.}

Additional file 2: eTable 1. Intraoperative and postoperative variables. Additional file 3: eTable 2. Follow-up variables.

Additional file 4: eTable 3. Baseline Demographic and clinical characteristics in propensity-matched cohort.

Additional file 5: eTable 4. the long-term mortality after surgery in different groups.

Additional file 6: eTable 5. Multivariate analysis of factors related to survival of patients from January 1, 2013 to September 1, 2019.

\section{Abbreviations}

CPB: Cardiopulmonary bypass; LVEF: Left ventricular ejection fraction; IABP: Intra-aortic balloon pump; CABG: Coronary artery bypass grafting; AVR: Aortic valve replacement or repair; MVR: Mitral valve replacement or repair; NYHA: New York heart association; AMI: Acute myocardial infarction; POD1: The first postoperative day; MV: Mechanical ventilation

\section{Acknowledgements}

Not applicable.

\section{Authors' contributions}

D.J.W designed the overall study with contributions from F.F.D and H.T.Z designed and carried out experiments, collected and analyzed data, and cowrote the paper. T. P assembly protocol, and analyzed data with X.L.T. All authors read and approved the final manuscript.

\section{Funding}

Author Dong-Jin Wang has received research grants from The Project of Invigorating Health Care through Science, Technology and Education (No. ZDXKA2016019) and National Key R\&D program of China (2016YFC1000808). The funding was used to pay the publication charges of the manuscript, but did not have a role in the study design, collection, analysis, interpretation of the data or writing the manuscript.

\section{Availability of data and materials}

The datasets generated and/or analyzed during the current study are not publicly available [some patients did not allow us to publish their medical records] but are available from the corresponding author upon reasonable request.

\section{Ethics approval and consent to participate}

The study was conducted in accordance with the principles of the Declaration of Helsinki, and the study protocol was approved by the Ethics Committee of Drum Tower Hospital. Because of the retrospective nature of the study, the patient's consent for inclusion was waived.
Consent for publication

Not applicable.

\section{Competing interests}

The authors declare that they have no competing interests.

Received: 12 May 2020 Accepted: 3 August 2020

Published online: 20 August 2020

\section{References}

1. Sharma UC, Barenbrug P, Pokharel S, Dassen WR, Pinto YM, Maessen JG. Systematic review of the outcome of aortic valve replacement in patients with aortic stenosis. Ann Thorac Surg. 2004;78:90-5.

2. Pieri M, Belletti A, Monaco F, Pisano A, Musu M, Dalessandro V, et al. Outcome of cardiac surgery in patients with low preoperative ejection fraction. BMC Anesthesiol. 2016;16:97-106.

3. Talwalkar NG, Earle NR, Earle EA, Lawrie GM. Mitral valve repair in patients with low left ventricular ejection fractions: early and late results. Chest. 2004; 126:709-15.

4. Kay JH, Zubiate P, Mendez MA, Vanstrom N, Yokoyama T, Gharavi MA Surgical treatment of mitral insufficiency secondary to coronary artery disease. J Thorac Cardiovasc Surg. 1980;79:12-8.

5. Bishay ES, McCarthy PM, Cosgrove DM, Hoercher KJ, Smedira NG, Mukherjee $D$, et al. Mitral valve surgery in patients with severe left ventricular dysfunction. Eur J Cardiothorac Surg. 2000;17:213-21.

6. Gambardella I, Gaudino M, Rahouma M, Farrington WJ, Khan FM, Hameed I, et al. Impact of left ventricular ejection fraction on the outcomes of open repair of descending thoracic and thoracoabdominal aneurysms. J Thorac Cardiovasc Surg. 2019;S0022-5223(19)33120-4.

7. luchi RJ, Scott SH, Deupree RH. Comparison of medical and surgical treatment for unstable angina pectoris: results of a veterans administration cooperation study. N Engl J Med. 1987;316:977-84.

8. Radovancevic B, Radovancevic R, Vrtovec B, Thomas CD, Frazier OH Outcomes in patients with low left ventricular ejection fraction after heart transplantation. Eur J Cardiothorac Surg. 2003;23(5):743-7.

9. Mancini DM, Eisen H, Kussmaul W, Mull R, Edmunds LH Jr, Wilson JR. Value of peak exercise oxygen consumption for optimal timing of cardiac transplantation in ambulatory patients with heart failure. Circulation. 1991; 83:778-86.

10. Hu SS, Dong NG, Wei X, Chen WL, Wang CS. Current situation of heart transplantation: Chinese heart transplant annual report 2013. Chin J Organ Transplant. 2014;35:324-8.

11. Hillis GS, Zehr KJ, Williams AW, Schaff HV, Orzulak TA, Daly RC, et al. Outcome of patients with low ejection fraction undergoing coronary artery bypass grafting: renal function and mortality after 3.8 years. Circulation. 2006; 4:114(1 Suppl):1414-9.

12. Bouchart F, Tabley A, Litzle PY, Haas-Hubscher C, Bessou JP, Soyer R. Myocardial revascularization in patients with severe ischemic left ventricular dysfunction. Long-term follow-up in 141 patients. Eur J Cardiothorac Surg. 2001;20:1157-62.

13. Trachiotis GD, Weintraub WS, Johnston TS, Jones EL, Guyton RA, Craver JM. Coronary artery bypass grafting in patients with advanced left ventricular dysfunction. Ann Thorac Surg. 1998;66:1632-9.

14. Thakar CV, Arrigain S, Worley S, Yared JP, Paganini EP. A clinical score to predict acute renal failure after cardiac surgery. J Am Soc Nephrol. 2005;16: $162-8$.

15. Royster RL. Butterworth 4th JF, Prough DS, Johnston WE, Thomas JL, Hogan $P E$, et al. Preoperative and intraoperative predictors of inotropic support and long- term outcome in patients having coronary artery bypass grafting Anesth Analg. 1991;72:729-36.

16. Topkara VK, Cheema FH, Kesavaramanujam S, Mercando ML, Cheema AF, Namerow PB, et al. Coronary artery bypass grafting in patients with low ejection fraction. Circulation. 2005:112(9 Suppl):1344-50.

17. Brinkman W, Herbert MA, O'Brien S, Filardo G, Prince S, Dewey $T$, et al. Preoperative $\beta$-blocker use in coronary artery bypass grafting surgery: national database analysis. JAMA Intern Med. 2014;174:1320-7.

18. O'Brien SM, Shahian DM, Filardo G, Ferraris VA, Haan CK, Rich JB, et al. The Society of Thoracic Surgeons 2008 cardiac surgery risk models: part 2 isolated valve surgery. Ann Thorac Surg. 2009;88(1 Suppl):S23-42.

19. McMurray JJ, Adamopoulos S, Anker SD, Anker, Auricchio A, Böhm M Dickstein K, et al. ESC Guidelines for the diagnosis and treatment of acute 
and chronic heart failure 2012: The Task Force for the Diagnosis and Treatment of Acute and Chronic Heart Failure 2012 of the European Society of Cardiology. Developed in collaboration with the Heart Failure Association (HFA) of the ESC. Eur Heart J. 2012:33:1787-847.

20. Pilarczyk K, Bauer A, Boening A, von der Brelie M, Eichler I, Gohrbandt B, et al. S3-guideline: recommendations for intra-aortic balloon pumping in cardiac surgery. Thorac Cardiovasc Surgery. 2015;63(suppl 2):S131-96.

21. The Chinese Expert Committee of Cardiac Intensive Medicine. Perioperative application of intra-aortic balloon pump in cardiac surgery. Net Med J China. 2017:97:2168-75.

22. Packer M, O'Connor CM, Ghali JK, Pressler ML, Carson PE, Belkin RN, et al. Effect of amlodipine on morbidity and mortality in severe chronic heart failure. Prospective randomized amlodipine survival evaluation study group. N Engl J Med. 1996;335(15):1107-14.

23. Pitt B, Poole-Wilson PA, Segal R, Martinez FA, Dickstein K, Camm AJ, et al. Effect of losartan compared with captopril on mortality in patients with symptomatic heart failure: randomised trial--the losartan heart failure survival study ELITE II. Lancet. 2000;355(9215):1582-7.

24. Stecker EC, Vickers C, Waltz J, Socoteanu C, John BT, Mariani R, et al. Population-based analysis of sudden cardiac death with and without left ventricular systolic dysfunction: two-year findings from the Oregon sudden unexpected death study. Jam Coll Cardiol. 2006;47(6):1161-6.

25. Vandenbroucke JP, von Elm E, Altman DG, Mulrow CD, Pocock SJ, Poole C, et al. Strengthening the reporting of observational studies in epidemiology (STROBE): explanation and elaboration. Int J Surg. 2014;12:1500-24.

26. Zhang $\mathrm{H}$, Yuan $\mathrm{X}$, Zhang $\mathrm{H}$, Chen $\mathrm{S}$, Zhao $\mathrm{Y}$, Hua $\mathrm{K}$, et al. Efficacy of longterm $\beta$-blocker therapy for secondary prevention of long-term outcomes after coronary artery bypass grafting surgery. Circulation. 2015;131:2194-201.

27. Kulik A, Ruel M, Jneid H, Ferguson TB, Hiratzka LF, Ikonomidis JS, et al. Secondary prevention after coronary artery bypass graft surgery: a scientific statement from the American Heart Association. Circulation. 2015;131:927-64

28. Connolly SJ, Cybulsky I, Lamy A, Roberts RS, O'brien B, Carroll S, et al. Betablocker length of stay (BLOS) study. Double-blind, placebo-controlled, randomized trial of prophylactic metoprolol for reduction of hospital length of stay after heart surgery: the beta-blocker length of stay (BLOS) study. Am Heart J. 2003;145:226-32

29. Chan AY, McAlister FA, Norris CM, Johnstone D, Bakal JA, Ross DB, et al. Effect of beta-blocker use on outcomes after discharge in patients who underwent cardiac surgery. J Thorac Cardiovasc Surg. 2010;140:182-7.

30. Paolillo S, Mapelli M, Bonomi A, Corrà U, Piepoli M, Veglia F. Etal. Prognostic role of $\beta$-blocker selectivity and dosage regimens in heart failure patients. Insights from the MECKI score database. Eur J Heart Fal. 2017;19:904-14.

31. Zangrillo A, Pappalardo F, Dossi R, Di Prima AL, Sassone ME, Greco T, et al. Preoperative intra-aortic balloon pump to reduce mortality in coronary artery bypass graft: a meta-analysis of randomized controlled trials. Crit Care. 2015;19:10.

\section{Publisher's Note}

Springer Nature remains neutral with regard to jurisdictional claims in published maps and institutional affiliations.

Ready to submit your research? Choose BMC and benefit from:

- fast, convenient online submission

- thorough peer review by experienced researchers in your field

- rapid publication on acceptance

- support for research data, including large and complex data types

- gold Open Access which fosters wider collaboration and increased citations

- maximum visibility for your research: over $100 \mathrm{M}$ website views per year

At $\mathrm{BMC}$, research is always in progress.

Learn more biomedcentral.com/submissions 